\section{The free recall and category clustering of factual material presented} in complex sentences

\author{
ELIZABETH BALSER* \\ Fairmont State College, Fairmont, W. Va. 26554
}

Lists of complex sentences taken from four factual articles were arranged in either a blocked or random order. These two lists and an additional list of 16 unrelated sentences were used to investigate free recall and clustering of prose material. Information given to $\mathrm{Ss}$ as to the clusterable nature of the material also varied. Results showed that Ss in the informed blocked condition performed better in both immediate and delayed recall and in clustering than those in any other condition. However, a more interesting finding was that the informed random group scored significantly higher than the uninformed random group. Moreover, because the uninformed random group and the group presented with unrelated sentences did not vary significantly, it appears that cueing, and not the list structure, was the more important factor influencing recall and clustering of factual material.

To date, the bulk of studies investigating category clustering during free recall have used stimulus lists composed of concrete nouns that can be organized into categories predetermined by the $E$. It has been well documented that during free recall of words from randomized lists, clusters of related words appear, particulariy when Ss are given cues pertraining to an organizational strategy that might be used during recall (Bousfield, 1953). Other studies indicate that when the stimulus words are presented in a logical context, the degree of recall and clustering of the stimulus words is increased (Gonzales \& Cofer, 1959; Deese, 1968).

However, information is lacking concerning the amount of recall and the degree of clustering of content material-specific facts-when presented in complex sentence patterns. Since Ss, using an organizational structure to recall words that had been presented in a randomized list, tend to have a higher recall rate (both immediate and delayed) than those who fail to cluster, it seems reasonable to predict that Ss might enhance their ability to recall facts presented in sentences arranged in random order by using a similar categorizing technique. Further, since information as to the clusterable nature of the stimulus word lists has raised levels of word recall (Loeb \& DeNike, 1969), a similar type of information should

*The author wishes to thank Dr. Richard Walls, whose encouragement and guidance were invaluable aids in preparing this study. Requests for reprints should be sent to Elizabeth Balser. Division of Language and Literature, Fairmont state College, Fairmont, W. Va. 26554. enhance Ss' ability to recall the material presented in prose passages. SUBJECTS

Eighty-eight freshman English students at Fairmont State College served as Ss. Twelve Sહ̈ failed to complete the second phase of testing in the experiment; therefore, 4 additional Ss were later tested in order to have $20 \mathrm{Ss}$ in each of four cells. Ss participated in the experiment as a part of the class requirements.

\section{MATERIALS AND CONDITIONS}

The stimulus materials consisted of 16 complex sentences, each containing two concrete facts. All sentences were taken from articles printed in college reading-improvement textbooks (Miller, 1964; Witty, 1962; Smith, Brownsword, \& Hanley, 1960), with the reading level standardized at approximately 11 th-grade level. The conditions varied according to the arrangement of the sentences and the instructions given.

Condition 1. Informed Blocked

Sixteen sentences were taken from articles on the following topics: eagles, sugar cane, contests, and the Pennsylvania Dutch. There were four sentences on each topic-for example, "Most unusual of all the inhabitants of the Pennsylvania Dutch country are the Amish farmers who live today much as their forefathers did more than 200 years ago"'; "A correspondence school which teaches the 'art of contesting' boasts of its 16,000 graduates who have won millions of dollars in prizes." The sentences were arranged as they appeared in the articles; that is, they were presented in a blocked presentation. However, successive sentences presented independent sentences or context for content and did not depend on other interpretation. The instructions, printed on a cover page, listed the four divisions of the material: "Study the following passages, keeping in mind that you will be asked to recall information from each. The passages concern: SUGAR CANE, CONTESTS, EAGLES, and THE PENNSYLVANIA DUTCH."

Condition 2: Informed Random

The same sentences were used; however, they were presented in random order. The instructions remained the same as in Condition 1 .

Condition 3: Uninformed Random

The sentences were presented in the same random order as in Condition 2 ; however, the instructions did not include the names of the content material groups.

Condition 4 : Independent

Sixteen unrelated sentences that ostensibly could not be clustered during recall were presented. The instructions were the same as in Condition 3.

\section{PROCEDURE}

The Ss participated in the investigation as part of their regular class activity. All four conditions were employed in each of three classes by randomly assigning test booklets. Each $S$ received a test booklet containing the instruction cover sheet, one page of stimulus sentences, and two blank pages for recall. After all Ss had read the instructions, they were given $5 \mathrm{~min}$ to study the sentences, followed by $17 \mathrm{~min}$ to record, using complete sentences, the information they remembered. Ss' response sheets were collected. Then a second study-recall trial was administered, using exactly the same procedure as during the first trial. At their next meeting (approximately $48 \mathrm{~h}$ later), they were asked to recall, with no additional study, the information presented in the sentences. Seventeen minutes was again allowed for responses. This recall trial was administered to investigate the effects of the treatments on delayed recall.

\section{RESULTS}

A total recall score was recorded for each $S$ by counting each fact correctly recalled. In this study, a fact was defined as any specific piece of information that was stated in the passage, e.g., "Sugar cane is harvested about 18 months after planting"; "The sugar cane stalks are similar in appearance to growing corn"; or "The first crop of sugar cane is called plant cane." No restriction was placed on the number of facts that could be recalled in one sentence. Table 1 shows the mean number of facts recalled by $S s$ in each condition on each trial. Separate one-way analyses of variance were computed for each of the three trials. These analyses yielded 
Table 1

Means and Standard Deviations of Recall Scores

\begin{tabular}{|c|c|c|c|c|c|c|}
\hline \multirow[b]{2}{*}{ Group } & \multicolumn{2}{|c|}{ Trial 1} & \multicolumn{2}{|c|}{ Trial 2} & \multicolumn{2}{|c|}{ Delayed Recall } \\
\hline & Mean & SD & Mean & SD & Mean & $\mathrm{SD}$ \\
\hline Informed Blocked & 20.70 & 3.29 & 26.65 & 3.66 & 24.75 & 5.00 \\
\hline Informed $R$ andom & 18.65 & 4.15 & 24.10 & 4.69 & 21.25 & 4.81 \\
\hline Uninformed $\mathrm{R}$ andom & 14.85 & 4.61 & 21.10 & 5.47 & 18.20 & 5.94 \\
\hline Independent & 12.50 & 4.06 & 20.50 & 3.90 & 16.25 & 4.97 \\
\hline
\end{tabular}

significant treatment effects for each trial, $F(3,76)=16.53, \quad p<.01$; $\mathrm{F}(3,76)=8.07, \mathrm{p}<.01 ; \mathrm{F}(3,76)=$ $10.19, \mathrm{p}<.01$, respectively. Multiple comparison $t$ tests indicated that only on the delayed recall trial did Ss in the informed blocked condition recall significantly $(\mathrm{p}<.05)$ more than those in the informed random condition. However, the informed random group recalled significantly more than the uninformed random group on Trial 1 $(p<.01)$, on Trial $2(p<.05)$, and on the delayed recall trial $(p<.05)$. The uninformed random and the independent groups did not differ significantly on any trial.

To determine the degree of clustering, both the ratio of repetition (RR) (Bousfield, 1953) and the stimulus category repetition (SCR) (Bousfield \& Bousfield, 1966) were used. $R R$ is defined as the ratio of the number of items that immediately follow another member of the same category to one less than the total number of items recalled. SCR represents the difference between the number of items that are observed to be clustered and the number that is expected by chance to be clustered. Scores from both measures compared favorably. Only analyses of the SCR scores are reported here; they appear in Table 2.

Analyses of variance for each of the three trials yielded significant effects for the clustering scores of three groups $[F(2,57)=14.79, \quad p<.01$; $\mathrm{F}(2,57)=13.15, \mathrm{p}<.01 ; \mathrm{F}(2,57)=$ $15.82, \mathrm{p}<.01$, respectively]. The independent group was not included in these analyses because the content material could not be clustered.

Groups receiving information pertaining to the topics involved clustered significantly more than the uninformed group, as the results of a multiple t test show. Informed

blocked clustered more than the informed random on all trials $(p<.05)$. Informed random clustered significantly more than uninformed random $(\mathrm{p}<.01$ on Trials 1 and 2 , and $p<.05$ on the delayed recall trial). The informed blocked clustered more than the uninformed random on all trials $(\mathrm{p}<.01)$.

\section{DISCUSSION}

Four interesting interpretations concerning clustering and recall can be made from the data recorded. First, it appears that the technique of clustering can be studied using material common to normal prose reading experiences. Ss exhibited the same clustering behavior when recalling facts contained in complex sentences as they did in reported studies where single words were the stimulus materials. That is, Ss receiving the material in an organized or blocked pattern clustered significantly more during recall than those Ss receiving the material in a random order.

Secondly, it appears that cueing, or giving pertinent information as to the clusterable nature of the material, also affects clustering. As might be expected, Ss in the informed blocked condition clustered significantly more than those in the informed random condition. This can be attributed to the contiguous nature of the material in the blocked condition. But Ss in the informed random condition clustered significantly more on all trials than those in the uninformed random condition. In this case, where arrangement of the material was identical, the significant differentiating factor appears to be the preparation given to the informed random $\mathrm{Ss}$ in the instructions.

Thirdly, the blocked arrangement of the material does not seem to affect immediate recall, as it did in related

Table 2

Means and Standard Deviations of Clustering Scores SCR Index

\begin{tabular}{|c|c|c|c|c|c|c|}
\hline \multirow[b]{2}{*}{ Group } & \multicolumn{2}{|c|}{ Trial 1} & \multicolumn{2}{|c|}{ Trial 2} & \multicolumn{2}{|c|}{ Delayed Recall } \\
\hline & Mean & SD & Mean & SD & Mean & SD \\
\hline Informed Blocked & 10.88 & 3.50 & 16.69 & 2.70 & 15.32 & 4.03 \\
\hline Informed $\mathrm{R}$ andom & 8.40 & 4.38 & 12.11 & 5.83 & 10.48 & 5.15 \\
\hline Uninformed Random & 4.42 & 3.41 & 9.00 & 5.19 & 7.35 & 4.27 \\
\hline
\end{tabular}

studies where blocked single words were used (Cofer, 1967, Dallett, 1964). In the present study, Ss in the informed blocked condition did not recall a significantly greater number of facts than did those Ss in the informed random condition on the immediate recall trials, 1 and 2 . However, on the delayed recall trial, Ss in the informed blocked condition did have greater recall than those in the informed random condition, indicating that the orderly arrangement of the material aided in delayed recall.

Fourthly, cueing seems to have an overall greater effect on recall than does the arrangement of the material. As reported above, the informed groups differed in recall on only one trial. However, for the informed random and the uninformed random groups, both of which worked with stimulus material presented in the same random arrangement, there was differential recall on all trials in favor of the former. It is also interesting to note that the uninformed random and the independent groups did not differ significantly from each other on any of the three trials. Thus, it does not appear that the nature of the material, i.e., whether or not it could be clustered, made a difference in the degree of recall.

\section{REFERENCES}

BOUSFIELD, W. A. The occurrence of clustering the recall of randomly arranged associates. Journal of General Psychology, 1953, 49, 229-240.

BOUSFIELD, A. K., \& BOUSFIELD, W. A. Measurement of clustering and of sequential constancies in repeated free recall. Psychological Reports, 1966, 19, recall. Ps 94.

COFER, C. Does conceptual clustering influence the amount retained in immediate free recall? In B. Kleinmuntz (Ed.), Concepts and the structure of memory. New York: Wiley, 1967

DALLETT, $K$. M. Number of categories and category information in free recall. Journal of Experimental Psychology, 1964, 68, 1-12.

DEESE, J. Influence of inter-item associative strength upon immediate free recall. Psychological Reports, 1959, 5, 305-312.

GONZALES, R. C., \& COFER, C. N. Exploratory studies of verbal context by means of clustering in free recall. Journa of Genetic Psychology, 1959, 95, 293-320.

LOEB, J., \& DeNIKE, L. D. Prediction of organization in free recall from reported learning strategy. Psychological Reports. $1969,25,631-636$.

MILLER, L. (Ed.) Increasing reading efficiency. (Rev. ed.) New York: Holt. Rinehart \& Winston, 1964.

SMITH, B., BROWNSWORD, W., \& HANLEY, G. (Eds.) Reading for power. Providence, R.I: Programs for Achievement in Reading, 1960.

WITTY, P. (Ed.) How to become a better reader. Chicago: Science Research Associates, 1962. 